\title{
AN EVALUATION OF CLASSROOM TEACHERS' OPINIONS ON ONLINE MATERIAL PREPARATION TRAINING THROUGH MOOC AND BLENDED EDUCATION MODEL
}

\author{
Dr. Ahmet ARNAVUT \\ ORCID: 0000-0002-2555-8209 \\ Faculty of Education, University of Kyrenia \\ Kyrenia, TURKISH REPUBLIC OF NORTHERN CYPRUS \\ Dr. Huseyin BICEN \\ ORCID: 0000-0002-9172-9790 \\ Ataturk Faculty of Education, Near East University \\ Nicosia, TURKISH REPUBLIC OF NORTHERN CYPRUS \\ Dr. Vasfi TUGUN \\ ORCID: 0000-0002-5306-5049 \\ TRNC Ministry of Education and Culture \\ Nicosia, TURKISH REPUBLIC OF NORTHERN CYPRUS
}

Received: 30/09/2019 Accepted: 12/06/2020

\begin{abstract}
The aim of this study is to increase the awareness of primary, secondary and high school teachers regarding Massive Open Online Courses (MOOC) as well as to help them to benefit from these media and to determine their opinions about these courses. As a result of the study, the results of the MOOC media through which the experimental group was trained and the blended learning training model of the control group were compared. Therefore, the aim is to provide guidance for the continual discussions about the effectiveness of MOOC. In the study, blended training was given to 33 teachers, whereas a complete online course on a formed platform was given to 34 teachers; consequently, the opinions and the success levels of the teachers were compared. The resulting data of the study was obtained from an opinion scale given to the teachers as well as a media evaluation form. The obtained qualitative and quantitative data were analysed and have been presented in the findings section.
\end{abstract}

Keywords: Massive Open Online Courses, MOOC, Blended Learning, Teachers, Web Based Learning, Moodle.

\section{INTRODUCTION}

The development of technologies used in education affects education media, teachers and also the learners themselves. Only the satisfaction of teachers and learners from these developing technologies would not be sufficient. Therefore, these media and materials should be used so that both learners and teachers can benefit accordingly (Aparicio, Oliveira, Bacao \& Painho, 2019). In order to make the currently used Massive Open Online Course (MOOC) media effective, the materials used in such media should be prepared in a conscious manner according to the learner profiles. The MOOC provide people with life-long selfdevelopment opportunities. Furthermore, while individuals are improving themselves, they also have new education possibilities through the ability to set their own education durations and times without impacting other areas of their lives (Patterson, 2018). In terms of the teaching profession, those working in this sector need to improve themselves continuously, particularly in this digital era where the students' profiles are continually changing (Bakayev, Vasilyeva, Kalmykova \& Razinkina, 2018). The elements required for attracting students' interest and attentions in the classroom would change every day as they meet new 
digital tools every day. Therefore, the teachers should choose the path that they will follow carefully in order to increase their educational quality and its efficiency. If it is assumed that the students' interest increases when digital tools are used along with developing technologies, it is evident that if digital tools-device and materials are used correctly in educational media, this can ease teachers' duties.

\section{Massive Open Online Courses (MOOC)}

The distance learning approach has developed to the point that MOOC are now available, which are free, open online courses that provide learners the unconditional right to participate as well as being open to everyone (Bozkurt, 2015). The accessible open course resources and social media are also included in MOOC media and those media are the ones of which the user interfaces are provided (Le Counte, Nafukho, Valentin, Johnson \& Valentin, 2015). Above all, the MOOC media are designed according to the knowledge levels, skills, interests, desires and learning needs of the learners so that they can organize their own participation (McAuley, Stewart, Siemens \& Cormier, 2010). Although widespread participation in open online courses existed in the past, the concept of MOOC first emerged in 2008 (Cormier, Stewart, Siemens \& McAuley, 2010).

MOOC have been developed as a result of "Connectivism Theory", which Siemens (2008) defined as the "Learning Theory of the Digital Era". The connectivism theory has arisen based on the developing technology and the changing human lives as a theory which defines learning through networks as a result of the studies conducted in the early 2000s by two Canadian academicians - George Siemens and Stephen Downes (Downes, 2012; Siemens, 2005).

\section{Blended Learning}

Unsal (2012) defined blended learning as "a teaching program that is most suitably and specially prepared for a specific group on 'average' level through combining new technologies, activities and facility types". However, Usta (2007) defined it as blended education that benefits from all types of technology and combines various distance and face-to-face learning models in the classroom. Although blended learning is defined differently by many researchers, they agree on the definition that blending learning involves "combining the Internet based education and face-to-face education in the traditional classroom manner". Additionally, the definition accepted in the literature about the blended learning method is " $30-80 \%$ of the lesson content within the tools as online, implementing the traditional learning method in the remaining time out of this period" (Allen \& Seaman, 2014; Porter, Graham, Spring \& Welch, 2014).

\section{PURPOSE OF THE STUDY}

In this study, the objectives include increasing the awareness of classroom teachers regarding MOOC media and materials as well as their ability to use such media effectively. Also, the data gathered from this study will act as a guide for researchers studying in this field, which is another objective. In order to measure the study productivity, the same training was given again to another group of classroom teachers using the blended learning model.

As well as teaching those models to the teachers in this course, they were asked to implement the things they learned during the course later in their own classrooms with their students. Therefore, the teachers would be able to use those media for their self-development and would also be able to apply the materials and things they had learned during the course in their own teaching practices.

The sub goals of the study are:

1. To determine the proficiency perspectives of the participants in the MOOC and Blended Learning groups before and after the course,

2. To determine their opinions about the prepared MOOC platform,

3. To determine whether they used the MOOC platform before and after the course,

4. To determine whether they will implement the things they learned during the course. 


\section{METHOD}

In this study, "online material design" training was given to the classroom teachers through the MOOC and blended training methods. As two separate groups, the teachers participated in the training as volunteers. The participating teachers from different schools were assigned to the groups based on a random placement method. The research is a mixed method research where questionnaire was administered to all the 67 teachers that participated and further form were filled in by all participating teachers at various Public Schools. The two group participants were trained on the same subject for a total of 7 weeks. During the course, the teachers were trained in terms of getting an e-mail address, preparing educational videos on the Internet, using the Moodle as both learners and teachers, creating documents and e-books on the Internet and using the cloud media effectively.

\section{Application}

While the MOOC group teachers completed the trainings interactively entirely on the Internet with each other and the training leader, the blended training group teachers met with the trainer 3 times a week using in-class media and maintained those trainings by benefitting from the online materials. For the teachers in the MOOC group, the MOOC media was prepared on the Moodle system and all lesson materials were shared on this platform with the participants.

\section{Study Group}

This study was conducted in the 2016-2017 fall semester with classroom teachers working in the Turkish Republic of North Cyprus. A total of 67 teachers from different branches, schools and cities voluntarily participated. While 33 teachers from different branches were placed in the blended group, 34 teachers from different branches were placed in the MOOC group. In total, 19 female $(57.6 \%)$ and 14 male $(42.4 \%)$ teachers were in the blended training group, while 20 male $(58.8 \%)$ and 14 female (41.2\%) teachers were in the MOOC group. The age of the participating teachers from different schools ranged from 25 to 55.

\section{Data Collection Tools}

According to the objectives of the study, the teachers were presented a proficiency perception scale about the effective use of materials on the MOOC platform and their preparation as a learner. Also, in order to determine whether the teachers benefited from the MOOC platform during the course, a platform evaluation form was presented to them which was prepared by the trainer by the end of the course so that their opinions about the media could be obtained. Through the opinion scale prepared by the course trainer, the teacher opinions were obtained regarding whether they would use the materials they had learned during the course in their lessons later.

\section{Proficiency Perception Scale about Massive Online Open Courses of Teachers}

Before creating the proficiency perception scale about MOOC, previously created scales about the MOOC were researched in both Turkish and international literature. No scales have been created about the MOOC. This scale will be implemented for the teachers in order to measure the proficiency perception on MOOC in terms of both learners and teachers. The item pool prepared during the scale creation was presented to 7 experts and after obtaining their opinions, the scale initially consisted of 40 items. This scale was administered to 355 teachers. In the first phase, the 40 item-scale was implemented to 200 teachers and then analyses were conducted; subsequently, 10 items that were deemed not to be suitable were removed. The resulting 30 -item scale was implemented to 155 teachers and the validity and reliability of the scale was assessed. The analysis results given below were gathered after the scale had been implemented for the last time. Factor analysis was conducted in order to determine the construct validity of the scale. In order to measure the data and sampling numbers' suitability according to the factor analysis, the KMO and Bartlett tests were conducted. The factor analysis is the strongest method in analysing construct validity and enables measurement with a 
lower number of factors by gathering together the variables that measure the same quality (Kerlinger, 1973; Ongel, 1975; Tabachnick \& Fidell, 1989). According to the evaluation of the results of factor analysis, the factor load values of items on the scale are suggested to be .45 or higher and the emphasis was on paying attention to the high load value on only one factor during the item choice. In order to determine the reliability of the scale, the Cronbach's alpha reliability coefficient of the scale dimensions according to the data was calculated. Since the Cronbach's alpha reliability coefficient is the internal consistency coefficient, the measured variable should be one dimensional. In this regard, a different reliability test was implemented to the scale's first factor and also a different reliability test was implemented to the scale's second factors. While the scale's first factor's Cronbach Alpha coefficient was .946; the scale's second factor Cronbach Alpha coefficient was found as .939 (Tan, 2001; Kiraz, 2003).

The KMO and Barlett test were first implemented to the scale. The KMO and Barlett test show the normality and the suitability for factor analysis. In the analysis after the pre-implementation for the scale, the KaiserMeyer-Olkin Measure of Sampling Adequacy (KMO) value was calculated as .639 and since it is $>.600$, it is meaningful. The Chi-Square value of the Bartlett's test was 15377.924 and the degree of freedom was 435, which indicates that it was meaningful $(\mathrm{p}=0.00, \mathrm{p}<0.05)$.

Table 1. KMO and Bartlett test

\begin{tabular}{lcc}
\hline Kaiser-Meyer-Olkin Measure of Sampling Adequacy. & .639 \\
\hline & Approx. Chi-Square & 15377.924 \\
Bartlett's Test of Sphericity & Df & 435 \\
& Sig. & .000 \\
\hline
\end{tabular}

\section{The Evaluation Form of Teachers for the Massive Open Online Course Media}

Attention was paid to particular details when preparing the MOOC media. Many different details can affect the learners' learning process such as the media where the course would be created and the material characteristics. For this reason, the learners' opinions about their course media, process and materials are very important for course experts. A qualitative evaluation form was created in order to obtain the learners' opinions about those criteria. Since all the participants in the blended and MOOC groups followed the same media, the form was presented to all the course participants. The views of 6 experts were obtained for the prepared form for the teachers, necessary revisions were made and lastly, it was implemented to the teachers at the end of the course.

\section{Perception Form about the Course}

During the course interview form preparation, the aim was to gather the teachers' opinions about the entire course process. During the course preparation, the main aim was to allow the teachers to benefit from the course as much as possible, to help them learn from the materials prepared during the course in terms of its positive and negative sides, to create their own materials and use those materials during their education as online to support the in-class education. Assuming that the participant teachers would want to improve themselves continuously, the first aim of the course was to use the MOOC as the theme of the course. The other aim was to contribute to either the teachers' life-long learning or to develop it as their hobby. In this regard, the teachers have evaluated the massive open online lessons and its contents in different aspects, the Moodle media established on this course in general, as well as the advantages and disadvantages of the group in which they participated. Five expert views were obtained during the Course Interview Form preparation and the final designed form was given to the teachers after the course. 


\section{MOOC Using States of the Teachers}

One of the objectives of the study is to increases the teachers' awareness of the MOOC media and to enable them to have continual self-development by using those media. Accordingly, teachers were asked whether they used MOOC media before and after the course in the demographic information section of the proficiency perception scale that had been improved.

\section{Data Evaluation}

In order to analyse the meaningfulness of the point differences related to the pre-test and post-test results, the paired sample t-test was used. For the explanation of the data differences, the general average was considered. The reason of the preference of those methods is due to the equal distribution of participant numbers. N Vivo 10 software was used for the gathered qualitative data analysis and they were explored via descriptive and systematic analysis.

\section{FINDINGS}

\section{The Proficiency Perspectives of Blended and MOOC Group Participants on Massive Open Online Courses Before and After the Course}

The results of the comparison between the proficiency perspectives of the blended and MOOC group participants in terms of the MOOC before and after the course have been given in Table 2.

Table 2. The proficiency perspectives of Blended and MOOC group participants on MOOC before and after the course

\begin{tabular}{|c|c|c|c|c|c|c|c|c|}
\hline \multicolumn{2}{|c|}{ Blended Learning Group } & $\mathrm{N}$ & $\bar{x}$ & SS & df & $\mathrm{t}$ & $\mathrm{p}$ & Explanation \\
\hline Average & Pre-test & 33 & 3.03 & .49 & 32 & -9.79 & .000 & $p<0.05$ \\
\hline \multirow[t]{2}{*}{ Point } & & & & & & & & Meaningful \\
\hline & Post-test & 33 & 3.92 & .40 & & & & \\
\hline \multicolumn{2}{|c|}{ MOOC Group } & $\mathrm{N}$ & $\bar{x}$ & SS & df & $\mathrm{t}$ & $\mathrm{p}$ & Explanation \\
\hline Average & Pre-test & 34 & 3.02 & .51 & 33 & -13.15 & .000 & $p<0.05$ \\
\hline \multirow[t]{2}{*}{ Point } & & & & & & & & Meaningful \\
\hline & Post-test & 34 & 4.30 & .29 & & & & \\
\hline
\end{tabular}

As the MOOC are a very new approach, they are not widely known. Since they only started to be used in Turkey in 2013, the number of related scientific studies is minimal. It is assumed that usage levels in the Turkish Republic of Northern Cyprus in regard to distance learning are similar, and the pre-test implemented to the participant teachers exhibited low results, which reinforces this expectation. When the results of the pre-test and post-test are compared, it is found that there is a meaningful difference between the two groups (For both groups $\mathrm{p}=.000, \mathrm{p}<0.05$ ).

\section{The Comparison of the Results of Evaluations by the Blended and MOOC Group Teachers}

The following table illustrates the evaluation results of the Blended and MOOC teacher groups in regard to the massive open online course media within the scope of the study. 
Table 3. Comparison of the results of evaluation by the Blended and MOOC group teachers

\begin{tabular}{cccccccc}
\hline & $\bar{X}$ & $\mathrm{~N}$ & $\mathrm{SS}$ & $\mathrm{t}$ & $\mathrm{df}$ & $\mathrm{p}$ & Explanation \\
\hline $\begin{array}{c}\text { Blended Learning } \\
\text { Group }\end{array}$ & 4.09 & 33 & .21 & & & & $\mathrm{p}>0.05$ \\
\hline MOOC Group & 4.11 & 34 & .20 & -.415 & 65 & .680 & No Meaningful \\
\hline
\end{tabular}

The participant teachers' opinions about the MOOC media were positive in both groups. On average the Blended group $(\bar{x}=4.09)$ and the MOOC group $(\bar{x}=4.11)$ scored the MOOC media and its materials for the course "Very good". While both groups evaluated the media in terms of different variables, no meaningful difference was found between the evaluation results of both groups $(p=.680, p>0.05)$.

The Blended group participants used this supportive media with the aim of filling in the variable scales and forms and solving the success test; on the other hand, the MOOC group participants followed the entire course from the beginning through this media. In other words, both groups used the media actively for seven weeks. By the end of the course, all the participants had created their own materials and courses on the same platform. In their study Simsek and Turan (2017), researched the usefulness of the MOOC on mobile media and they made suggestions accordingly based on the results in order to increase this usefulness. They evaluated the most commonly used types of MOOC media, such as Coursera, Udacity and Udemy in regard to their usefulness in courses in terms of gender, age, technological literacy and online course experience variables on mobile media. According to the results, statistical differences were found in terms of interface quality, information quality, usefulness and system utility among the evaluated three systems. This study shows that there might be differences in the variables of the most commonly used massive open online course media, such as system utility, usefulness, materials and content.

\section{The Presentation of Frequency and Percentage of State of Using the MOOC by the Teachers before and After the Course}

On Table 4; frequency and percentage of state of using the MOOC by the teachers before and after the course have been given.

Table 4. The distribution of MOOC use of teachers before and after the course

\begin{tabular}{cccccccccc}
\hline & \multicolumn{2}{c}{ Blended Learning Group } & \multicolumn{3}{c}{ MOOC Group } \\
\hline \multirow{2}{*}{ MOOC use of teachers } & \multicolumn{2}{c}{ Before } & \multicolumn{2}{c}{ After } & \multicolumn{2}{c}{ Before } & \multicolumn{2}{c}{ After } \\
\hline Using & $\mathrm{F}$ & $\%$ & $\mathrm{~F}$ & $\%$ & $\mathrm{~F}$ & $\%$ & $\mathrm{~F}$ & $\%$ \\
Not Using & 6 & 18.2 & 24 & 72.7 & 9 & 26.5 & 30 & 88.2 \\
Total & 27 & 81.8 & 9 & 27.3 & 25 & 73.5 & 4 & 11.8 \\
\hline
\end{tabular}

As there has been a positive development in the proficiency perceptions of teachers on MOOC after the course, they also have the same positivity in the state of their using those media. After the course, the participant teachers visited the MOOC media more and registered as members. After the course, the number of participant teachers in the blended group who stated that they would benefit from those media increased from $18.2 \%$ to $72.7 \%$. In other words, 24 out of 33 people benefited from the MOOC media. By the end of the course, the number of people in the blended group who continued not to use MOOC media was 9 (27.3\%). However, 30 people $(88.2 \%)$ from the MOOC participant group registered and are now using those media. The number of people in this group who continue not to benefit from MOOC media is 4 (11.8\%). 


\section{The Blended and MOOC group Teachers' Opinions about Using the Things They had learned during the Course in Their Own Lessons}

Table 5 presents the blended and MOOC group teachers' opinions about using the things they had learned during the Online Educational Material Design course in their own lessons in tabular format based on the analysis reulsts, some of the teacher perspectives have been given directly without any changes.

Table 5. The distribution of teacher opinions about implementing the things they had learned during the course

\begin{tabular}{lc}
\hline Using the Learned Elements in the Lessons ( $\mathrm{n}=67)$ & $\mathrm{f}$ \\
\hline The materials used make the learning entertaining & 48 \\
I believe that it would motivate my students & 58 \\
My students also have the right to benefit from these opportunities & 44 \\
It makes learning more effective & 55 \\
\hline
\end{tabular}

The Massive open online course materials are materials that are prepared on digital media but could be used in traditional education. The teachers can upload the supportive materials into the MOOC groups in their in-class education and use them as well as creating faster and more effective learning. After the course, the teachers can create their own massive open online course based on the things that had learned during the course and can provide education to learners from all over the world. They can also improve the materials they had learned during the course and integrate them into their class training and motivate the young people during the lessons.

In this direction, the teachers' opinions about using the elements they had learned in their own lessons were asked. The answers show that the teachers were positive about being trained with the massive open online course materials and would like their students to also benefit from those opportunities. According to the conversations with teachers and their opinions during the course, from the beginning of the course, the teachers had already started to use the elements they had learned in their own classrooms. The teachers stated that from the day they had begun to use those methods and materials, the students became more entertained and did not realise when the lesson had finished. They also often mentioned that the students wanted to be trained with those materials on a regular basis. These positive reactions of the teachers are due to the training they received and this was reflected in their students. According to both groups' teachers' opinions, they were very satisfied with the materials, video durations and flow, explanation styles that they mentioned all the time. Due to this increased level of satisfaction, they used the materials in their classrooms, which increased the student motivation and believed that if those who were not using them chose to do so, this would also increase their students' motivation.

The aim of participating in the course was not only to learn, but also to share the elements they had learned with their students and colleagues which are stated by the teachers and they claimed everyone had the right to learn and benefit from the possibilities and technologies. Additionally, they stated that this kind of training was better and more entertaining, which meant that they were highly motivated to use them in their own lessons. Some of the opinions of the teachers about using the elements they had learned during the course in their own lessons are as follows:

"...exactly my aim was this when I participated in this course. From now on I am able to prepare richer lesson content and can present to my students through using different media." (Interview form: T42).

“...Yes, I am thinking. I already teach by using the available technologies in my school. It grabs my students' attention. With the new technology, the students learn better through being entertained." (Interview form: T59).

"...I will definitely use. I believe all the teachers should benefit from these opportunities and provide more quality education." (Interview form: T18). 
"...If the lesson management systems such as Moodle are established in the school, I would like to use them regularly. The subjects that the students don't understand inside the class would be beneficial if they are watched and listened on the computer media later. Also, I am thinking of creating tests on the systems and preparing supportive activities from the external resources." (Interview form: T16).

"...Yes, I am thinking. I would like to have a teaching manner, materials and content that motivate, enliven and entertain the learners so that the education is more qualified." (Interview form: T45).

"... This course in which I participated has made an unbelievable contribution to my lessons, social life and learning. I definitely would like my students also to benefit from those opportunities and their benefits." (Interview form: T31).

"...Especially I would like to use the materials we have learned in my own lessons to present a more qualified educational manner so that it would be more informative for the students." (Interview form: T10).

"... I would like to inform my students during the first weeks of semester about those topics and to use these opportunities during the semester together with my students." (Interview form: T39).

"...I began using the elements I have learned from the first week of the course in my own lessons. Feedback given by students reflected that this has increased their motivation and the lessons have been more interesting." (Interview form: T51).

"... Thanks to this course and media, when we prepare lesson materials, we have more freedom compared to the traditional ones and also we have the opportunity to deliver contents to the students in the out of the lesson times, which helps us improve our teaching jobs. This media and associated materials could motive students more and when they are learning the content, the students are livelier and more entertained." (Interview form: T61).

\section{RESULTS AND DISCUSSION}

Meaningful differences were found in terms of the proficiency perception tests that were applied to the Blended and MOOC group teachers before and after the course. The reason for this is that the MOOC are new and they first started being used Turkey in 2013 (Aydin, 2017). Other reasons include that the related studies in this country are very rare and the teachers are unaware of those novelties. It is assumed that the lecturers and teachers working in this country have only been learning and using the MOOC lessons very recently. One of the sub-objectives is to prepare the teachers for this course as both learners and teachers and to enable them to benefit from the courses during their teaching and learning lives. Therefore, according to the results obtained, there is a meaningful difference in the pre-test and post-test comparison of the Blended and MOOC group teachers' proficiency perceptions about the massive open online lessons, which shows that this study has achieved its goals.

In another analysis, it is believed that the MOOC group teachers have more positive proficiency perception states for the MOOC than the blended group teachers, because they followed the whole course through the MOOC media (which was created for this course) and they therefore they were prepared mentally and in terms of their potential abilities

As another objective of the study, the teachers evaluated this prepared massive open online course media in terms of its usefulness and materials. During the course, the teachers created materials that would be used in the MOOC and they were able to see the pros and cons of those media by analysing the MOOC media which, were prepared by both experts and novices in the field. By the end of the course, the teachers were asked to evaluate the MOOC media that had been prepared for them and the obtained data were analysed. According to the analysis, both blended and MOOC group teachers' opinions about the MOOC media and materials were very positive. Both groups of teachers stated that the media was perfectly prepared and there was no meaningful difference between the opinions of both group teachers about the media. Another aim of the study was to increase the teachers' awareness of MOOC and to use them in both their individual and professional development as well as in other subjects. As result of the study, it is possible to say that this objective was achieved. 
As a result of the study, it is possible to state that the teachers in both groups made positive progress in using the MOOC. While only a limited number of teachers in the blended group used the MOOC for their self-development, by the end of the course, more than half of the blended group teachers benefitted from those media. Among the MOOC group teachers, while a small number benefitted from those media, by the end of the course, a significant number of the teachers used those media for individual and professional development. The advantage of the materials used in MOOC for the teachers is that they can use them in the traditional teaching style also. Therefore, the teachers were asked whether they thought about using the elements they had learned in the course in an online environment or in traditional lessons. In this regard, it has been found that most of the teachers who started learning these materials began using them in their own lessons from the first day of learning. As both users and the learners, the teachers who gained knowledge from those materials stated that those materials made learning more effective and would motivate students more. The teachers said that they were aware of the new opportunities, effective materials and were satisfied with the training course. Additionally, the teachers noted that the students should be aware of those novelty materials which are necessary because they can receive considerable benefits by using them. In addition to these positive opinions, the teachers mentioned that the MOOC materials made the learning more effective.

\title{
FUTURE STUDIES
}

The MOOC have been considered as the variables of this study which are discussed in conjunction with blended learning, the validity and efficiency of which has been proven by experts. In order to increase the validity of the obtained data, these types of studies should be conducted by comparing the MOOC with different educational models to different samples. Although the same method and technique could be implemented in the future studies, changing the scope and sampling in different countries with more participants would not prevent the results from being compared and also the obtained results would provide guidance for researchers who study in the field of web based education or distance learning. In addition, it can be said that the country where the research is applied, the number of participants and the professional field are among the limitations of the research.

\section{BIODATA and CONTACT ADDRESSES of AUTHORS}

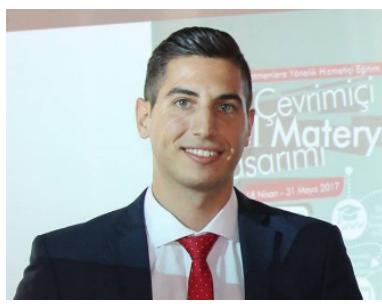

Dr. Ahmet ARNAVUT is a assist. professor of education faculty at university of kyrenia. dr. arnavut gained his ph.d. in computer education and instructional technology at december, 2017. his academic interest areas are open and distance learning, education futures, e-learning, use of internet in education, education technologies, mobile learning and collaborative learning. he has journal articles published in international indexes, other national and international articles, national book chapters, papers submitted to international meetings. he is also active in the referee boards of international journals.

\author{
Ahmet ARNAVUT \\ Faculty of Education \\ Address: University of Kyrenia, 99010, Kyrenia, CYPRUS \\ Phone: +903926502600 , \\ E-mail:ahmet.arnavut@kyrenia.edu.tr
}




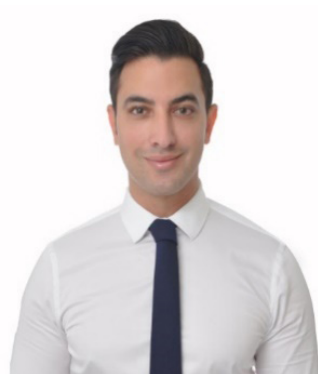

Dr. Huseyin BICEN was born in nicosia on december 31, 1986. he completed his undergraduate, graduate and doctorate programs in the department of computer education and instructional technologies at near east university. he worked as a lecturer at the near east university in 2007-2012. bicen, who was appointed as a faculty member since 2012, received the title of associate professor in 2015. He has been working as the head of "human resources development in education" since 2013. bicen, who was the founding director of the distance learning center in 2013-2019, has been serving as the vice dean of the faculty of open and distance education in 2015-2019 and as the acting dean of the relevant faculty since 2019. Huseyin Bicen has high-level articles titled distance education, social media in education, technology addiction, massive open online courses, artificial intelligence, gamification, flipped classroom, etc., national and international published conference papers and book chapters with academic content which have been indexed in the social sciences index to date. he is also active in the scientific boards of international conferences, projects and referee boards of journals.

\section{Huseyin BICEN}

Computer Education and Instructional Technology, Ataturk Faculty of Education

Address: NEAR EAST University, 99010, Nicosia, CYPRUS

Phone: +90392 6802000/5104,

E-mail: huseyin.bicen@neu.edu.tr

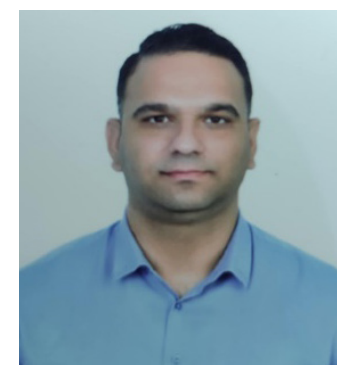

Dr. Vasfi TUGUN is a assist. prof. dr. of trnc ministry of education and culture. he gained his ph.d. in computer education and instructional technology at august, 2015. he worked at university of kyrenia from 2015 to 2019. his academic interest areas are computer education, educational technology, social network, educational hypermedia and multimedia, educational interfaces, open and distance learning, e-learning, flipped learning, cyber behaviors and use of internet in education. he has articles published in international indexes and other national and international articles, papers submitted to international meetings.

\section{Vasfi TUGUN}

TRNC Ministry of Education and Culture

address: Trnc Ministry of Education and Culture, 99010, Nicosia, CYPRUS

Phone: +905488527891,

E-mail: vasfitugun@gmail.com

\section{REFERENCES}

Allen, I. E. \& Seaman, J. (2014). Grade change. Tracking Online Education in the United States. Babson Survey Research Group and Quahog Research Group, LLC. Retrieved on 28.09.018 from: http:// sloanconsortium.org/publications/survey/grade-change-2013

Aparicio, M., Oliveira, T., Bacao, F., \& Painho, M. (2019). Gamification: A key determinant of massive open online course (MOOC) success. Information \& Management, 56(1), 39-54. doi:10.1016/j. im.2018.06.003

Aydin, C. H. (2017). Current Status of the MOOC Movement in the World and Reaction of the Turkish Higher Education Institutions. Open Praxis, 9(1), 59. https://doi.org/10.5944/openpraxis.9.1.463

Bakayev, V., Vasilyeva, V., Kalmykova, S., \& Razinkina, E. (2018). Theory of physical culture-a massive open online course in educational process. Journal of Physical Education and Sport, 18(1), 293-297. https://doi.org/10.7752/jpes.2018.01039

Bozkurt, A. (2015). Kitlesel acik cevrimici dersler (Massive Open Online Courses-MOOC) ve sayisal bilgi caginda yasamboyu ogrenme firsati. Acikogretim Uygulamalari ve Arastirmalari Dergisi, 1(1), 5681. Retrieved from https://dergipark.org.tr/en/pub/auad/issue/3030/42090 
Cormier, D., Stewart, B., Siemens, G. \& McAuley, A. (2010). What is a MOOC? Retreived on 28.08.2019 from: https://www.youtube.com/watch?v=eW3gMGqcZQc

Downes, S. (2008). Connectivism: A theory of personal learning. Retreived on 28.08.19 from: https://www. slideshare.net/Downes/connectivism-a-theory-of-personal-learning

Downes, S. (2012). Connectivism and connective knowledge. Essays on meaning and learning networks. National Research Council Canada.

Kerlinger, F. N., \& Gagne, R. M. (1973). Review of research in education. Itasca, IL: Peacock.

LeCounte, J. F., Nafukho, F., Valentin, M., Johnson, D. \& Valentin, C. (2015). The MOOC: Characteristics, Benefits, and Challenges. Handbook of Research on Innovative Technology Integration in Higher Education, 228. https://doi.org/10.4018/978-1-4666-8170-5.ch011

McAuley, A., Stewart, B., Siemens, G. \& Cormier, D. (2010). The MOOC model for digital practice.

Ongel, E. (1975). Faktor Cozumune Giris: Onemli Bilesen Cozumu ve Uygulamasi. Ankara. Turkey.

Patterson, R. W. (2018). Can behavioral tools improve online student outcomes? Experimental evidence from a massive open online course. Journal of Economic Behavior \& Organization, 153, 293-321. doi:10.1016/j.jebo.2018.06.017

Porter, W. W., Graham, C. R., Spring, K. A., \& Welch, K. R. (2014). Blended learning in higher education: Institutional adoption and implementation. Computers \& Education, 75, 185-195. doi:10.1016/j. compedu.2014.02.011

Siemens, G. (2005). Connectivism: Learning as network-creation. ASTD Learning News, 10(1), 1-28.

Simsek, E., I. \& Turan, B. O. (2017). Mobil Ortamlarda Kitlesel Acik Cevrimici Derslerin (KACD) Kullanilabilirliginin Degerlendirilmesi. Mersin University, Journal of the Faculty of Education, 13(2). http://dx.doi.org/10.17860/mersinefd.336745

Tabachnick, B. G., Fidell, L. S., \& Ullman, J. B. (2019). Using multivariate statistics. Boston: Pearson.

Usta, E. (2007). Harmanlanmis ogrenme ve cevrimici ogrenme ortamlarinin akademik basari ve doyuma etkisi. (Unpublished PHD Thesis) Gazi University, Institute of Educational Sciences, Ankara, Turkey.

Unsal, H. (2012). Harmanlanmis Ogrenmenin Basari ve Motivasyona Etkisi. Journal of Turkish Educational Sciences, 10(1), 1-27. 